Research letter

\title{
Psychological defense peculiarities in patients with brain tumor induced epilepsy
}

\author{
Alvin Acas Miranda, Vladimir Alekseevich Zhadnov \\ Ryazan State Medical University n.a. I.P. Pavlov, Ryazan, Russia
}

Received 12 October 2016, Revised 17 November 2016, Accepted 9 December 2016

(C) 2016, Miranda A.A., Zhadnov V.A.

(C) 2016, Russian Open Medical Journal

Abstract: Aim - The aim of this study was to assess the levels of psychological distress in patients with brain tumor induced epilepsy as well as evaluation of predominant psychological defence mechanisms.

Material and Methods - Eighty-five adult patients diagnosed with brain tumors and admitted at the neurosurgical department, Ryazan Regional Clinical Hospital between September 1, 2015 and October 1, 2016 were included in the study. The main group had two subgroups: 20 patients with brain tumor induced epilepsy and 65 patients with no epileptic seizures. Twenty relatively healthy subjects constituted the control group. Psychometric tests including Life Style Index, Level of Subjective Control and Beck Depression Inventory in the form of questionaires were used in the study.

Results - Statistically significant strong positive as well as negative correlations were established amongst intellectualization, productiveness, projection and health relations parameters in patients with brain tumor induced epilepsy as compared to moderate correlations in patients with no epileptic seizures. Patients with symptomatic epilepsy demonstrated constructive methods of psychological defence as compared to patients with no seizures. However, patients with no seizures, based on predominance of outward hostility projection are likely to have a more favourable long-term outcome.

Conclusion - Life Style Index and Level of Subjective Control psychometric tests are an important component in the complex evaluation and treatment of patients with brain tumors and should be advocated as useful additional investigation method based on their prognostic value in patients with possible terminal illness.

Keywords: brain tumors, epileptic seizures, psychological defence

Cite as Miranda AA, Zhadnov VA. Psychological defense peculiarities in patients with brain tumor induced epilepsy. Russian Open Medical Journal 2017; 6 : e0105.

Correspondence to Alvin Acas Miranda. Address: Room 4, 18, Lesoparkovaya str., Ryazan, 390006, Russia. Tel: 8(920) 983-97-57.

E-mail: alvinmiranda@yahoo.com

\section{Introduction}

Psychological stress is known for its detrimental outcome in terms of clinical course of the disease as well as quality of life in cancer patients. Inability to cope in such stressful conditions puts such patients at risk from destructive social and associated emotional defence mechanisms. Complexity, heterogenicity and multifactorial pathogenesis of cancer has been extensively correlated with stressful life and significantly associated with immune-neuro-endocrine remodulation through a myriad of pathways at molecular level which either result into attenuative constructive responses or inability to compensate, which eventually lead to disturbance in stress-adaptive equilibrium [1].

Psychiatric comorbidity has significant influence on the quality of life of a patient [2-4].

Numerous literature sources confirm that epilepsy associated psycho-inclinations should be described as a complex condition with possible subcategories rather than a separate identity [5]. Understanding the intertwined relationships amoungst different psychological defence mechanisms in patients with brain tumors is of utmost significance in structuring complex somatopsychological treatment methods to improve disease outcome.

\section{Material and Methods \\ Patients}

Eighty-five adult patients (age: $57.8 \pm 15.8$ years) diagnosed with brain tumors and admitted at the Neurosurgical Department of Ryazan Regional Clinical Hospital (Ryazan, Russia) between September 1, 2015 and October 1, 2016 as well as 20 (age: $45.0 \pm 12.1$ years) relatively healthy subjects were included in the study. All patients included in the study complied and signed informed conscents reviewed and approved by the Ethical Committee as well as the Scientific Council of Ryazan State Medical University n.a. I.P. Pavlov (Ryazan, Russia).

Patients were divided into the following subgroups:

- Patients with brain tumor induced epilepsy (Group I),

- Patients with brain tumors without epileptic seizures (Group II),

- Relatively healthy control subjects (Group III).

Exclusion criteria: co-morbid organic brain disoders and acute organic brain syndromes. 


\section{Methods}

In this study the following questionairs were used: Life Style Index (LSI) [6], Level of Subjective Control (LSC) [7], and Beck Depression Inventory (BDI) [8].

Life Style Index (LSI): Psychometric testing method based on psycho-evolutionary theory of R. Plutchik (1979) and structured personality theory of $\mathrm{H}$. Kellerman, intended and specified for diagnosis of various mechanisms of psychological defence. The LSI questionnaire comprises of 97 "yes" or "no" questions $[6,9]$. LSI test was selected in this study to acess different mechanisms of psychological defence as well as quantifying the extent of stress on these adaptive mechanisms caused by brain tumors and brain tumor induced epilepsy.

Level of Subjective Control (LSC): The LSC questionnaire technique is a modified version of the questionnaire of the American psychologist J. Rotter and modified by E.F. Bazhina, E.A. Golynkina and A.M. Etkind [7], that allows estimating the level of subjective control over a variety of situations, that is, determining the extent of human responsibility for their actions and their lives [10]. The authors have developed a technique based on the hierarchical structure of the system of behavior regulation so that the questionnaire includes a composite index of individual LSC (level of subjective control, which is invariant to the particular indicators of activity), two measures of the average level of generality, differentiated depending on the emotional character of these situations and a number of situation-specific indicators. 44 statements presented visually are offered to the subjects, who must agree with each of the statements or reject it by answering "yes" or "no" [11].

The level of subjective control is one of the important characteristics of self-awareness, which generates a sense of responsibility and willingness to be active. LSC in this study is aimed at helping us understand the relationship between psychological characteristics of patients faced with a possible terminal illness.

The Beck Depression Inventory (BDI) is a widely used 21question grading inventory by Aaron $\mathrm{T}$. Beck used in clinical psychology for highlighting and quantifying the level of depression in a person. BDI is a relatively quick psychometric test requiring elementary reading comprehensive skills, providing a researcher indepth perspective of a wide range of cognitive discrapencies as well as physically manifesting depressive symptoms [12].

\section{Statistical analysis}

Statistical data analysis was conducted by SPSS 23.0 (SPSS Inc, USA). Distribution of all variables was close to normal. Mean and standard error of mean $(\mathrm{m})$ were used to describe the variables. Spearman correlation coefficient ( $r S$ ) was used to evaluate the relationship among variables. Nominal variables were shown as percent (\%). Significance of differences of parametric variables in these groups was assessed by Student's criterion. Results were claimed as statistically significant at the commonly used significance level $P<0.05$

As usual values, $0.0<\mathrm{rS}<0.4$ were interpreted as practically (clinically) negligible, $0.4<\mathrm{rS}<0.6$ as weak, $0.6<\mathrm{rS}<0.8$ as moderate, and $0.8<\mathrm{rS}<1.0$ as a strong correlation. Negative sign correlated to negative correlation in the same order.
Table 1. Spearman's correlation coefficients and importance levels between LSI and LSC parameters among studied patients and subgroups

\begin{tabular}{lc:cc:cc}
\hline \multicolumn{2}{c}{ Group I } & \multicolumn{2}{c}{ Group II } & \multicolumn{2}{c}{ Group III } \\
\hline E-Iz & $0.8^{* *}$ & Io-In & $0.7^{* *}$ & Io-Is & $0.9^{* *}$ \\
B-Im & $-0.8^{* *}$ & In-Ip & $0.7^{* *}$ & lo-Iz & $0.8^{* *}$ \\
A-H & $0.7^{*}$ & Io-Ip & $0.7^{*}$ & Is-Im & $0.8^{* *}$ \\
G-Ip & $-0.7^{*}$ & A-D & $0.6^{* *}$ & lo-Ip & $0.7^{* *}$ \\
A-Io & $0.7^{*}$ & E-H & $0.6^{* *}$ & Io-Im & $0.7^{* *}$ \\
Io-In & $0.7^{*}$ & Io-Is & $0.6^{* *}$ & In-Im & $0.7^{* *}$ \\
Io-Is & $0.7^{*}$ & Io-Im & $0.6^{* *}$ & Is-Iz & $0.7^{* *}$ \\
Io-Iz & $0.7^{*}$ & B-In & $-0.4^{*}$ & D-G & $-0.6^{* *}$ \\
In-Ip & $0.7^{*}$ & & & & \\
\hline
\end{tabular}

* is $\mathrm{P}<0.05 ; * *$ is $\mathrm{P}<0.01$. A, Denial; $\mathrm{B}$, Repression; C, Regression; D, Compensation; E, Projection, $F$, Displacement; $G$, Intellectualization; $H$, Reaction formation; Io, General internality; Id, Achievement; In, Internality of failure; Is, Family relations; Ip, Production; Im, Interpersonal relationships; Iz, Relation to health and disease.

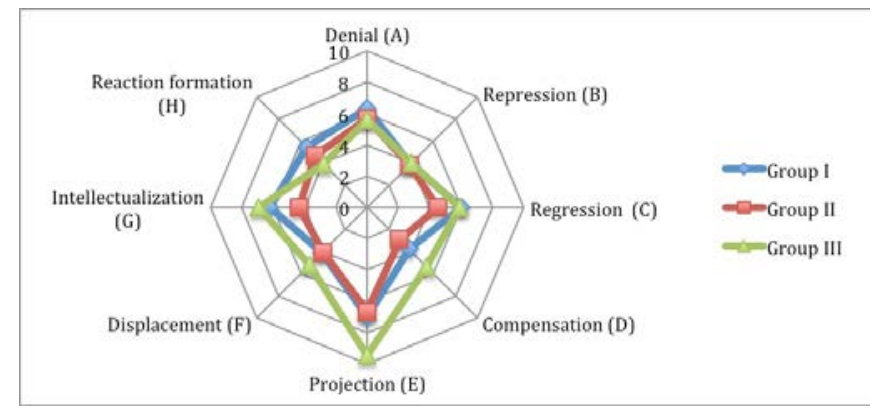

Figure 1. Radar diagram illustrating mechenanisms of psychological defence in study sample.

\section{Results}

Nonparametric Spearman's rank correlation coefficient rS revealed statistically significant correlations between LSI and LSC parameters. Strong correlations in-group of patients with brain tumor induced epilepsy were observed between intellectualization and production (positive), projection and relation to health and disease (positive), Repression and interpersonal relationships (negative) and general internality with relation to health and disease (negative). Moderate correlations were consistent ingroup of patients without epileptic seizures (Table 1).

In patients with brain tumor induced epilepsy, the leading mechanisms of psychological defence are intellectualization (39\%), projection (22\%) and compensation (11\%) as compared to projection (48\%), denial (22\%) and displacement (9\%) seen in patients without epileptic sezures. Along with these psychological defence mechanisms, the two groups of patients revealed different hierarchy of level of subjective control. The leading parameters in patients with brain tumor induced epilepsy were: Family relations (16\%), interpersonal relationships (13\%) and relation to health and disease (9\%). The dominating parameters (Figure 1) in patients without epileptic seizures were Interpersonal relationships $(17 \%)$, relation to health and disease $(13 \%)$ and family relations $(9 \%)$.

In patients with brain tumor induced epilepsy, projection and intellectualization were lower by $26 \%$ and $30 \%$ respectively $(P<0.05)$ than control group as compared to $29 \%$ and $46 \%$ decrese $(P<0.05)$ in patients without epileptic seizures. We revealed significant difference in internality of failure in both groups of patients (Table 2 ) compared to the control group ( $20 \%$ decrease, 
$\mathrm{P}<0.05$, in patients with brain tumor induced epilepsy and $17 \%$ decrease, $\mathrm{P}<0.05$, in patients without epileptic seizures).

Becks depressive inventory revealed nonsignificant $(P>0.05)$ higher depression rate in patients without epileptic seizures. Gender peculiarities however revealed a $5.2 \%$ higher rate of depression in female $(\mathrm{P}<0.05)$ compared to male patients in the main group. Female patients were also found to have $38 \%, 29 \%$ and $25 \%$ increase $(P<0.05)$ in compensation, denial and regression respectively in defence mechanisms as compared to male patients. Gender peculiarity results revealed in these patients may serve as a platform for future research in this area.

\section{Discussion}

Patients with brain tumor induced epilepsy were found to have relatively more constructive psychological defence mechanisms as compared to patients without epileptic seizures who demonstrate significantly distressed and destructive associated psychological defence mechanisms. However it must be stated that predominance of projection in patients without epileptic seizures may be a good prognostic sign in the long run due to the fact that these patients have the ability to extrovert negativity on to others instead of having it "consume" them inside. This outwards hostility direction means that these patients are less likely to utilize destructive defence mechanisms such as denial.

Along with constructive and to an extent "more favourable" defence mechanisms, patients with brain tumor induced epilepsy demonstrate tendency to stronger family ties, interpersonal relationships and relation to personal health and disease as opposed to predominance of interpersonal relationships seen in patients without epileptic seizures.

Correlation between subjective control and psychological defence mechanisms in patients with brain tumors and epilepsy are widely discussed separately in majority of modern literature. However, literature on such correlations in patients with symptomatic epilepsy co-morbid with brain tumors is difficult to come across. Constructive versus destructive mechanisms of psychological defence in brain tumor patients depending on the presence or absence of symptomatic epilepsy revealed through psychometric testing are a perspective method of determining intra-personality and inter-personality conflicts as well as their influence on emotional and cognitive spheres. Enormous research in fields of neurology and neuro-psychology are needed until we fully understand the complexity of such psychological defence mechanisms. Nevertheless, including LSI and LSC tests amongst other psychometric tests in routine diagnostics for patients with brain tumor induced epilepsy may be the first step towards an "elaborate prognosis" for such patients.

\section{Conclusion}

Patients with brain tumor induced epilepsy demonstrate strong positive and negative predominant intergroup corelations of paired LSI and LSC parameters (E-Iz and B-Im), while patients without epileptic seizures demonstrated intragroup moderate positive correlations of paired parameters (Io-In, Io-Ip and In-Ip).

LSI results revealed constructive mechanisms of psychological defence (intellectualization, projection and compensation) in patients with brain tumor induced epilepsy as compared to destructive defence mechanisms (denial and displacement) in patients without epileptic seizures.
Table 2. LSI, LSC and BDI parameters in studied groups

\begin{tabular}{llll}
\hline Parameters & $\begin{array}{l}\text { Group I } \\
(n=20)\end{array}$ & $\begin{array}{l}\text { Group II } \\
(n=65)\end{array}$ & $\begin{array}{l}\text { Group III } \\
(n=20)\end{array}$ \\
\hline Denial (A) & $6.33 \pm 0.73$ & $5.64 \pm 0.52$ & $5.61 \pm 0.55$ \\
Repression (B) & $3.89 \pm 0.61$ & $3.82 \pm 0.32$ & $4.01 \pm 0.44$ \\
Regression (C) & $6.01 \pm 0.83^{\mathrm{c}}$ & $4.50 \pm 0.33^{\mathrm{b}}$ & $5.89 \pm 0.71$ \\
Compensation (D) & $3.78 \pm 0.66^{\mathrm{a}}$ & $2.91 \pm 0.38^{\mathrm{b}}$ & $5.39 \pm 0.49$ \\
Projection (E) & $7.01 \pm 0.85^{\mathrm{a}}$ & $6.68 \pm 0.48^{\mathrm{b}}$ & $9.44 \pm 0.57$ \\
Displacement (F) & $4.11 \pm 0.82$ & $4.05 \pm 0.39$ & $5.22 \pm 0.65$ \\
Intellectualization (G) & $6.22 \pm 0.71^{\mathrm{c}}$ & $4.36 \pm 0.35^{\mathrm{b}}$ & $6.94 \pm 0.49$ \\
Reaction formation (H) & $5.44 \pm 0.77$ & $4.68 \pm 0.54$ & $3.94 \pm 0.51$ \\
General Internality (Io) & $3.02 \pm 0.29$ & $2.91 \pm 0.19$ & $3.28 \pm 0.27$ \\
Achievement (Id) & $4.33 \pm 0.17$ & $4.50 \pm 0.16$ & $4.33 \pm 0.29$ \\
Internality of Failure (In) & $3.33 \pm 0.29^{\mathrm{a}}$ & $3.45 \pm 0.24^{\mathrm{b}}$ & $4.17 \pm 0.28$ \\
Family Relations (Is) & $5.33 \pm 0.33^{\mathrm{c}}$ & $4.68 \pm 0.17$ & $5.04 \pm 0.28$ \\
Production (Ip) & $2.78 \pm 0.22$ & $2.95 \pm 0.18$ & $3.06 \pm 0.17$ \\
Interpersonal & $4.44 \pm 0.29$ & $4.68 \pm 0.21$ & $5.06 \pm 0.21$ \\
relationships (Im) & & & \\
Relation to Health and & $4.22 \pm 0.22$ & $4.41 \pm 0.18^{\mathrm{b}}$ & $3.83 \pm 0.27$ \\
disease (Iz) & & & \\
Depression (BDI) & $28.44 \pm 0.97$ & $27.73 \pm 0.63$ & $29.33 \pm 1.34$ \\
\hline
\end{tabular}

Data presented as mean with standard error of mean $-\mathrm{M} \pm \mathrm{m}$.

$\mathrm{P}<0.05$ for comparison: ${ }^{\mathrm{a}}$ - between Groups I and III; ${ }^{\mathrm{b}}$-between Groups II and III; ${ }^{\mathrm{C}}$ - between Groups I and II.

LSC results in patients with brain tumor induced epilepsy show predominance of family relations followed by interpersonal relationships and relation to health and disease, while in patients without epileptic seizures, dominance of interpersonal relationships is observed followed by relations to health and disease and finally family relations.

Statistically unsignificant depression rates were attained in the study population through BDI psychometric test.

Psychometric tests are an important component in the complex evaluation and treatment of patients with brain tumors, and to a large extent, patients with brain tumor induced epilepsy. LSI and LSC psychometric tests however demonstrate significantly higher potential as psychoanalytic and psycho-prognostic tools compared to BDI based on their strong inter and intra-group parameter correlations

LSI and LSC psychometric tests should be advocated as useful additional investigation method based on their prognostic value in patients with possible terminal illness.

\section{Acknowledgments}

The study was conducted in the Department of Neurosurgery of Ryazan Regional Clinical Hospital (Ryazan, Russia). Thanks to Mr. Amrah Magerramov for supplying technical assistance with data collection and issuing. Reference editing and writing style review was performed by $\mathrm{Dr}$. Liana V. Lorina (MD, Associate Professor, Department of Neurology, Neurosurgery and Medical Genetics, Ryazan State Medical University n.a. I.P. Pavlov, Ryazan, Russia)

\section{Conflict of Interest}

The authors declared no potential conflicts of interests with respect to the research, authorship, and publication of this article.

\section{References}

1. Denaro N, Tomasello L, Russi EG. Cancer and stress: what's matter? from epidemiology: the psychologist and oncologist point of view. $J$ Cancer Ther Res 2014; 3: 6. https://dx.doi.org/10.7243/2049-7962-3-6. 
2. Gaitatzis A, Trimble MR, Sander JW. The psychiatric comorbidity of epilepsy. Acta Neurol Scand 2004; 110(4): 207-220. https://dx.doi.org/10.1111/i.1600-0404.2004.00324.x.

3. Krishnamoorthy ES. Psychiatric issues in epilepsy. Curr Opinion Neurol 2001; 14: 217-24. https://www.ncbi.nlm.nih.gov/pubmed/11262739.

4. Shetty T, Trimble MR. The Bear Fedio Inventory: twenty years on. J Epilepsy 1997; 10: 254-262. http://dx.doi.org/10.1016/S08966974(97)00058-3.

5. Adachi N, Matsuura M, Hara T, Oana Y, Okubo $\mathrm{Y}$, Kato M, Onuma T. Psychosis and epilepsy: are interictal and postictal psychoses distinct clinical entities? Epilepsia 2002; 43(12): 1574-1582. http://dx.doi.org/10.1046/i.1528-1157.2002.22402.x.

6. Plutchik R, Henry Kellerman $H$, Conte HR. A structural theory of ego defenses and emotions. In: Emotions in Personality and Psychopathology. Part I. New York, USA: Plenum Press, 1979: 227-257. http://dx.doi.org/10.1007/978-1-4613-2892-6 9.

7. Bazhin EF, Golynkina EA, Etkind AM. The method of investigation of the subjective level of control. Psychological Journal 1984; 5(3): 27-36. Russian

8. Beck AT. Depression: Causes and Treatment. Philadelphia, USA: University of Pennsylvania Press, 1972.

9. Plutchik R. A psycho-evolutionary theory of emotions. Social Science Information 1989; 21: 529-553. http://iournals.sagepub.com/doi/citedby/10.1177/053901882021004 $\underline{003}$.

10. Rotter JB. Generalized expectancies of internal versus external control of reinforcements. Psychol Monogr 1966; 80(1): 1-28. https://psycnet.apa.org/doi/10.1037/h0092976.

11. Gorskaya N, Glyzina V. Level of Subjective Control (LSC) in the area of interpersonal relations as one of the fundamental needs of the individual. Middle-East Journal of Scientific Research (Socio-Economic Sciences and Humanities) 2013; 13: 34-37. http://dx.doi.org/10.5829/idosi.mejsr.2013.13.sesh.1407.

12. Groth-Marnat G. Handbook of psychological assessment, 4th Edition. John Wiley \& Sons, 2003; 862 p.

Authors:

Alvin Acas Miranda - MD, MSc Neurosurgery, PhD student, Ryazan State Medical University n.a. I.P. Pavlov, Ryazan, Russia. http://orcid.org/00000002-2465-3001.

Vladimir Alekseevich Zhadnov - MD, PhD, Professor, Consultant Neurosurgeon, Head of Department of Neurology, Neurosurgery and Medical Genetics, Ryazan State Medical University n.a. I.P. Pavlov, Ryazan, Russia. http://orcid.org/0000-0002-5973-1196. 